\title{
Cómo se llegó a parar el Metro de Madrid: Un análisis interaccionista de los procesos previos a una huelga total ${ }^{1}$
}

\author{
Nicholas Pohl ${ }^{2}$
}

Recibido 05/02/2020; Aceptado 05/07/2020

Resumen. En junio de 2010, un día después de la aplicación de un recorte salarial en Metro de Madrid, las/os trabajadoras/ es fueron a una huelga total. Paralizaron el tráfico subterráneo durante 48 horas y colapsaron el tráfico en el centro de la capital. Con esta investigación intento mostrar cómo las/os trabajadoras/es llegaron a paralizar el Metro de Madrid. El análisis se basa en dos tipos de datos: las circulares sindicales que se publicaron en el momento de los eventos y entrevistas semi-directivas realizadas a posteriori con representantes sindicales y trabajadoras/es. A partir de estos datos identifico las secuencias de interacción entre las/os trabajadoras/es, los sindicatos, la dirección de la empresa y el gobierno regional que precedieron a la huelga total. Los resultados muestran que, en lugar de una respuesta supuestamente natural ante un grave ataque, esta huelga total debería de hecho considerarse como un efecto de composición derivado de las interacciones encadenadas entre actores múltiples e interdependientes.

Palabras clave: Huelgas; movimientos obreros; Gran Recesión; medidas de austeridad; interaccionismo; España.

\section{[en] How Madrid Underground came to a halt: An interactionist analysis of the processes prior to a total strike}

\begin{abstract}
In June 2010, one day after austerity measures had been applied to Madrid Underground, the underground workers went on a total strike. They paralyzed the underground traffic during 48 hours and caused major traffic gridlocks in the city center. The aim of the present research is to understand how this total strike came about. The analysis rests on two types of data: union circular letters produced at the time of the events and semi-directive interviews conducted a posteriori with union representatives and ordinary workers. Together, these data allow one to reconstruct the sequences of interaction between workers, unions, the company management, and the regional government, which preceded the total strike. The findings show that instead of a seemingly natural response to a harsh attack, the total strike should in fact be regarded as a composition effect resulting from nested interactions between multiple and interdependent players.
\end{abstract}

Keywords: Strikes; labor movements; Great Recession; austerity measures; interactionism; Spain.

Sumario: 1. Introducción 2. Reconstruir configuraciones a través de un análisis de circulares sindicales 3. Cómo se produjo la huelga total 3.1. El inicio de 2010: una atención desigual a la crisis económica y conflictos habituales entre los sindicatos 3.2. El anuncio de las medidas de austeridad: incertidumbre entre los sindicatos y un aislamiento cada vez mayor de UGT 3.3. Los recortes llegan a Metro de Madrid: los sindicatos se unen frente al menoscabo de los procedimientos habituales de negociación colectiva 3.4. "Y yo más, y yo más": una asamblea de trabajadoras/es con una fuerte competencia entre representantes sindicales 3.5. Sin dar marcha atrás, sin reconciliación: punto muerto tras la asamblea de trabajadoras/es 4. Algunas conclusiones 5. Bibliografía.

Cómo citar: Pohl, N. Cómo se llegó a parar el Metro de Madrid: Un análisis interaccionista de los procesos previos a una huelga total. Sociología del Trabajo, $\mathrm{n}^{\circ} 96$ (2020), 47-60

El presente artículo es una versión modificada de un texto previamente publicado en la revista Social Movement Studies (Pohl, 2020). El trabajo de investigación fue apoyado por el Fondo Nacional Suizo para la Investigación Científica (P1LAP1_178066). El texto fue solicitado al autor por el Consejo de Redacción de la Revista, tras ser presentado en la V Reunión Intercongresual del Comité de Sociología del Trabajo de la FES, Barcelona, Septiembre de 2018. Ha sido traducido del inglés al castellano por Vanessa Amessa, de Around The World Transaltions.

2 Instituto de Estudios Políticos, Universidad de Lausana, Suiza.

E-mail: nicholas.poh1@unil.ch. 


\section{Introducción}

Hace diez años, en junio de 2010, el gobierno regional de Madrid anunció un recorte salarial del 5\% para las/os trabajadoras/es de Metro de Madrid. Unas semanas después, Metro de Madrid se paralizó por completo. Las/os trabajadoras/es se declararon en huelga total, poniendo en riesgo sus puestos de trabajo al incumplir los servicios mínimos obligatorios, ${ }^{3}$ - para así rechazar el inminente recorte salarial. Teniendo en cuenta la fuerza de los sindicatos de Metro de Madrid y la larga historia de conflictos laborales dentro de la empresa, una medida tan drástica no resulta del todo una sorpresa. Al fin y al cabo ¿por qué no deberían las/os trabajadoras/es con previa participación en huelgas recurrir a medidas drásticas cuando sufren graves ataques? Si bien este modo de pensar mecanicista puede resultar tentador, en el mejor de los casos oculta, y en el peor de los casos distorsiona, procesos más complejos que subyacen al origen de conflictos colectivos. Con este artículo, mi objetivo es proporcionar información sobre algunos de estos procesos más complejos.

Por este motivo adopto una perspectiva interaccionista y combino los conocimientos de los estudios sobre movimientos sociales (Fillieule y Broqua, 2020; Jabola-Carolus et al., 2018; Jasper y Duyvendak, 2015) con la literatura en materia de huelgas como secuencias de interacción (Biggs, 2002; Franzosi, 1995). Intento evitar un pensamiento mecanicista en las cadenas causales lineales al hacer especial énfasis en las dinámicas procesuales y las interacciones encadenadas entre los múltiples actores implicados. En este sentido, considero que actores como los sindicatos no interactúan con "contextos" ni "estructuras", sino con otros actores específicos como las/os directivos de las empresas o las/os representantes del gobierno (Jasper, 2015).

Siguiendo a Elias (1984), estas interacciones tienen lugar dentro de unas "configuraciones", es decir, unas redes de relaciones de competencia entre actores con una dependencia recíproca. Las configuraciones nunca son estáticas: pueden establecerse en equilibrios de poder pasajeros, pero las relaciones siempre se encuentran en tensión y son susceptibles de sufrir cambios menores o mayores. La noción de configuración por tanto resulta útil para comprender de una manera dinámica la complejidad de las relaciones entre múltiples actores, aliados y opuestos (Fillieule y Broqua, 2020). Además, esta noción nos invita a ir más allá del análisis de las divisiones entre categorías tales como trabajadoras/es, sindicatos, administraciones de empresas y el estado, y tener en cuenta las relaciones de competencia que existen dentro de estos grupos de actores. Examinar las interacciones dentro de esos grupos de actores muestra que no son homogéneos, sino que también albergan conflictos (internos). En este artículo, presto especial atención a las alianzas y divisiones entre los diferentes sindicatos en Metro de Madrid, susceptibles de sufrir cambios.

Ser conscientes de la interdependencia entre actores también evita concepciones demasiado estratégicas de los procesos que se estudian. ${ }^{4}$ De hecho, cuanto más equivalentes sean las relaciones de poder entre los actores, más difícil será para uno de los actores poder influir (de manera única) en el resultado del "juego". La combinación imprevisible de reproches recíprocos tanto simultáneos como sucesivos entre los actores puede conducir, además, a los llamados "efectos de composición", es decir, "efectos que ningún actor esperaba de antemano [y que] una vez desencadenados, [conllevan] efectos restrictivos para todos" (Fillieule y Broqua, 2020: 7). Por lo tanto, una perspectiva interaccionista parece particularmente adecuada para deconstruir grupos aparentemente homogéneos como "trabajadoras/es", "empleadoras/es" o "el estado", además de narraciones demasiado lineales sobre el surgimiento de conflictos laborales.

El artículo está organizado de la manera que se indica a continuación: en la siguiente sección describo los datos empíricos y hago hincapié en la utilidad de basarse en materiales creados durante el transcurso de los eventos. El núcleo del artículo examina las secuencias de interacción que precedieron a la huelga total. En la conclusión realizo un resumen de los hallazgos, proporciono argumentos adicionales para adoptar una perspectiva interaccionista sobre la aparición de las huelgas y propongo algunos caminos para futuras investigaciones.

\section{Reconstruir configuraciones a través de un análisis de circulares sindicales}

Han pasado muchos años entre el momento de la huelga total y el análisis que hago del evento. Esto plantea inevitablemente algunos problemas metodológicos: ¿cómo puedo reconstruir de manera fiel el origen de esta huelga total? ¿Cuáles son los procedimientos más fiables para la recopilación y análisis de datos para evitar las "ilusiones etiológicas" (Dobry, 2009), es decir, las reconstrucciones excesivamente lineales de las cadenas causales a posteriori? Para este análisis, tomé la decisión de seguir el enfoque de Tacket (1996) y examinar principalmente los documentos que

En España, los servicios que contribuyen al cumplimiento de los derechos constitucionales entran en la categoría de "servicios esenciales". Para estos servicios, el derecho de huelga se encuentra limitado y se decretan servicios mínimos (Vivero Serrano, 2002). Al considerarse que el transporte público garantiza el derecho constitucional de libre circulación, estos servicios también deben operar con unos "niveles mínimos" durante los períodos de huelga. Dependiendo de la cantidad esperada de pasajeras/os, los servicios mínimos decretados para Metro de Madrid generalmente varían entre el 40 y el $60 \%$ del funcionamiento habitual.

4 Si bien la perspectiva interaccionista presenta ventajas evidentes, también conlleva el riesgo de generar una investigación demasiado centrada en el presente (u hodiecéntrica, en términos de Goudblom, 1977, véase también Duyvendak y Fillieule, 2015). Limitarse a secuencias de interacciones durante períodos cortos de tiempo comporta el riesgo de olvidar que los actores existen antes de que estas interacciones concretas se den: todos los actores tienen su propia historia, la cual da forma a sus opciones de actuación (concebibles). Si bien soy consciente de este riesgo, el alcance limitado de este artículo no me permite proporcionar informes históricos completos de los diferentes actores. Siempre que sea posible, sigo aportando contenido histórico a los procesos y actores que forman parte del estudio. 
fueron creados in actu, es decir, durante el transcurso de los eventos. Los materiales retrospectivos (como memorias o entrevistas realizadas posteriormente) tienen, de hecho, desventajas no desdeñables cuando se trata de examinar procesos e interacciones, ya que las partes involucradas tienden a racionalizar y dar coherencia y consistencia a acciones pasadas.

De los materiales creados in actu, me centro en las circulares sindicales que fueron publicadas por los siete sindicatos que formaron parte del comité de empresa de la compañía en 2010 (véase la Tabla 1 con una breve descripción de los sindicatos y sus características respectivas). Las circulares son un medio de comunicación a disposición tanto del comité de empresa como de los sindicatos que lo integran. Dos veces por semana, la empresa distribuye las circulares más recientes por cada uno de los centros de trabajo. Desde 2008, gracias a la intranet de la empresa, las circulares resultan aún más accesibles para las/os trabajadoras/es.

Tabla 1. Los sindicatos de Metro de Madrid y sus respectivas características, ordenados por el número de escaños que ocupaban en el comité de empresa de la compañía en 2010.

\begin{tabular}{|c|c|c|c|c|}
\hline Nombre y sigla & $\begin{array}{l}\text { Número de esca- } \\
\text { ños en el comité } \\
\text { de empresa. }\end{array}$ & $\begin{array}{l}\text { Forma de organización y afiliación } \\
\text { sindical }\end{array}$ & $\begin{array}{l}\text { Postura politica } \\
\text { con la que se } \\
\text { autoidentifican }\end{array}$ & Predisposición para hacer huelga ${ }^{\mathrm{a}}$ \\
\hline $\begin{array}{l}\text { Sindicato de Con- } \\
\text { ductores de Metro de } \\
\text { Madrid (SCMM) }\end{array}$ & 8 & $\begin{array}{l}\text { Sindicato que se limita a Metro de } \\
\text { Madrid; organiza únicamente a las/os } \\
\text { conductoras/es }\end{array}$ & $\begin{array}{l}\text { "Políticamente } \\
\text { independiente" }\end{array}$ & $\begin{array}{l}\text { Partidario de las huelgas, pero solo si } \\
\text { afecta a las condiciones de trabajo de las/ } \\
\text { os conductoras/es. }\end{array}$ \\
\hline $\begin{array}{l}\text { Comisiones Obreras } \\
(\mathrm{CCOO})\end{array}$ & 7 & $\begin{array}{l}\text { Sección sindical de uno de los dos } \\
\text { principales sindicatos españoles; } \\
\text { organizan a todos las/os trabajadoras/ } \\
\text { es del metro }\end{array}$ & $\begin{array}{l}\text { "Sindicato de } \\
\text { clase", histórica- } \\
\text { mente cercano a } \\
\text { la izquierda co- } \\
\text { munista }\end{array}$ & $\begin{array}{l}\text { Tiene una larga historia de luchas sindica- } \\
\text { les dentro de Metro de Madrid. }\end{array}$ \\
\hline $\begin{array}{l}\text { Unión General de } \\
\text { Trabajadores (UGT) }\end{array}$ & 6 & $\begin{array}{l}\text { Sección sindical de uno de los dos } \\
\text { principales sindicatos españoles; } \\
\text { organizan a todos las/os trabajadoras/ } \\
\text { es del metro }\end{array}$ & $\begin{array}{l}\text { "Sindicato de } \\
\text { clase", histórica- } \\
\text { mente cercano al } \\
\text { partido socialde- } \\
\text { mócrata }\end{array}$ & $\begin{array}{l}\text { Tiene un papel controvertido en las luchas } \\
\text { laborales de Metro de Madrid, especial- } \\
\text { mente debido a su firma en un pacto de } \\
\text { eficacia limitada (que está acotado a las/ } \\
\text { os miembros del sindicato) durante la } \\
\text { negociación de un convenio colectivo en } \\
\text { 1998. Comisiones Obreras y Solidaridad } \\
\text { Obrera consideraron esta acción como } \\
\text { una „puñalada por la espalda“. }\end{array}$ \\
\hline $\begin{array}{l}\text { Confederación Sin- } \\
\text { dical Solidaridad } \\
\text { Obrera (SO) }\end{array}$ & 5 & $\begin{array}{l}\text { Principal sección sindical de un peque- } \\
\text { ño sindicato estatal; organiza a todas/ } \\
\text { os las/os trabajadoras/es del metro. }\end{array}$ & $\begin{array}{l}\text { "Anarcosindica- } \\
\text { lista" }\end{array}$ & $\begin{array}{l}\text { El sindicato más propenso a las huelgas } \\
\text { en Metro de Madrid, habiendo convocado } \\
\text { repetidamente huelgas sin mayor respaldo } \\
\text { sindical. }\end{array}$ \\
\hline $\begin{array}{l}\text { Sindicato Libre } \\
\text { Metro y Suburbano } \\
\text { (SLMS) }\end{array}$ & 4 & $\begin{array}{l}\text { Sindicato que se limita a Metro de } \\
\text { Madrid; organiza a todas/os las/os } \\
\text { trabajadoras/es del metro. }\end{array}$ & $\begin{array}{l}\text { "Políticamente } \\
\text { independiente"c }\end{array}$ & $\begin{array}{l}\text { Considera a las/os trabajadoras/es y a la } \\
\text { dirección de la empresa como socias/os } \\
\text { y, por lo tanto, es más bien contrario a las } \\
\text { huelgas. }\end{array}$ \\
\hline $\begin{array}{l}\text { Sindicato de Técnicos } \\
\text { de Metro de Madrid } \\
\text { (STMM) }\end{array}$ & 2 & $\begin{array}{l}\text { Sindicato que se limita a Metro de Ma- } \\
\text { drid; únicamente organiza al personal } \\
\text { técnico titulado. }\end{array}$ & $\begin{array}{l}\text { "Políticamente } \\
\text { independiente" }\end{array}$ & $\begin{array}{l}\text { Contrario a las huelgas debido a la es- } \\
\text { trecha relación de su electorado con la } \\
\text { dirección de la empresa. }\end{array}$ \\
\hline $\begin{array}{l}\text { Sindicato de Esta- } \\
\text { ciones de Metro de } \\
\text { Madrid (SEMM) }\end{array}$ & 1 & $\begin{array}{l}\text { Sindicato que se limita a Metro de } \\
\text { Madrid; organiza al personal de esta- } \\
\text { ciones de metro únicamente. }\end{array}$ & $\begin{array}{l}\text { "Políticamente } \\
\text { independiente" }\end{array}$ & $\begin{array}{l}\text { Convoca huelgas solo si afecta a las } \\
\text { condiciones de trabajo del personal de las } \\
\text { estaciones }\end{array}$ \\
\hline
\end{tabular}

a La evaluación de su predisposición a la huelga resulta difícil y arriesgada, especialmente en una sola frase. Sin embargo, esta información resulta importante para comprender las interacciones previas a la huelga total. También revela el faccionalismo predominante, que se tuvo que superar (o dejar de lado de manera temporal) para que la huelga fuera posible.

b Como resultado de una escisión de otro sindicato anarcosindicalista llamado Confederación General del Trabajo (CGT) en 1990 (veáse Pohl, 2016).

c Sin embargo, su homónimo en las décadas de 1920 y 1930 tuvo su origen en la derecha tradicionalista y tuvo como objetivo construir un contrapoder sindical a la anarcosindicalista Confederación Nacional del Trabajo (Winston, 1982: 562).

Fuente: elaboración propia.

Las circulares constituyen un medio de comunicación esencial para los sindicatos porque llegan tanto al conjunto del personal como a la dirección de la empresa. Los sindicatos las usan para convocar a las/os trabajadoras/es, pero también para ejercer presión sobre la dirección o sobre otros sindicatos. Las circulares ofrecen muchas ventajas frente a otro tipo de fuentes: (1) Permiten incluir los puntos de vista de todos los sindicatos del comité de empresa. Esto no sería posible con otros recursos, como los medios de comunicación, donde solo algunas/os dirigentes sindicales tienen voz. (2) Los sindicatos utilizan las circulares de forma habitual, lo que permite analizar las interacciones en- 
tre diferentes actores fuera de los momentos extraordinarios (es decir, cuando los sindicatos reciben poca atención por parte de los medios de comunicación). (3) Las circulares pueden considerarse como un espacio antagónico en el que los sindicatos compiten por el apoyo de las/os trabajadoras/es. Los sindicatos critican a la administración de la empresa o a los gobiernos (locales, regionales y nacionales), pero también discuten entre sí sobre determinados problemas. Por consiguiente, las circulares permiten examinar tanto las interacciones "verticales" (con las/os trabajadoras/es o la dirección de la empresa) como las interacciones "horizontales" (entre los diferentes sindicatos). (5) Por último, estas circulares suponen testimonios de primera mano de las diferentes interacciones, e imparciales frente a posibles relatos posteriores. Permiten, por lo tanto, captar los momentos de fricción e incertidumbre que caracterizan las interacciones.

Si bien presenta muchas ventajas, el análisis de estas circulares también conlleva algunos riesgos. En primer lugar, su contenido no debe tomarse al pie de la letra. La anticipación a posibles reacciones (más que nada, rechazos) de otros sindicatos probablemente provoca una suerte de autoequilibrado y, por lo tanto, aumenta la veracidad de las circulares. Sin embargo, las circulares siguen cumpliendo el propósito estratégico de obtener apoyo entre las/os trabajadoras/es, que son quienes votan a los sindicatos que formarán parte (o no) del comité de empresa. Por ende, estos documentos siempre deben analizarse teniendo en cuenta las premisas de la competencia entre sindicatos. Además, las circulares son una mera forma de interacción entre muchas otras. Antes de la huelga, se llevaban a cabo dos asambleas generales de trabajadoras/es y muchas reuniones presenciales, formales e informales, entre sindicatos o entre los sindicatos y la dirección de la empresa. Las circulares solo proporcionan una información fragmentada y parcial sobre estas interacciones. Para completar esta información tuve que hacer un uso aislado de fuentes retrospectivas (en forma de entrevistas semi-directivas).

El período de estudio comienza a principios de 2010 y termina el día anterior a la huelga total (28 de junio). ${ }^{5}$ En este período examiné un conjunto completo de 350 circulares publicadas por los sindicatos y el comité de empresa en Metro de Madrid. Tras un „análisis de contenido cualitativo estructurado“ (Mayring, 2014), creé un subconjunto de 137 circulares entre las que destacaban 87 de ellas por mencionar de manera explícita al menos a otro sindicato en Metro de Madrid, 23 de ellas incluían al menos una referencia a la crisis económica y 27 circulares cumplían ambos criterios.

Las circulares que incluyen referencias a otros sindicatos fueron seleccionadas para identificar las interacciones que se producían de manera horizontal entre los sindicatos y, en consecuencia, también las alianzas cambiantes y las disputas entre sí. Las circulares que hacían referencia a la crisis económica fueron empleadas con el fin de examinar los marcos relacionados con la crisis e incluir las interacciones realizadas de manera vertical. Distingo tres tipos de marcos: diagnósticos de problemas y atribuciones de culpa (marcos de diagnóstico), articulaciones de soluciones (marcos de pronóstico) y fundamentos para la toma de acciones (marcos de motivación) cuando se habían realizado llamamientos a la acción (Snow y Benford, 1988). Respecto a las interacciones relacionadas con la crisis, examiné las interacciones horizontales entre los sindicatos de Metro de Madrid recurriendo a las 27 circulares relacionadas con la crisis y que hacían una referencia explícita a otros sindicatos. Las interacciones verticales (relacionadas con la crisis) se incluyeron al examinar las frecuentes referencias a los gobiernos nacionales y regionales o a la administración de la empresa (especialmente en forma de atribuciones de culpa), así como a las/os trabajadores de Metro de Madrid (a quienes se dirigían los marcos de diagnóstico, pronóstico y de motivación; véase Snow et al., 1986). La Tabla 2 ofrece una visión general de las circulares que fueron publicadas por los diferentes sindicatos entre el 1 de enero y el 28 de junio de 2010.

Tabla 2. Número de circulares publicadas entre el 1 de enero de 2010 y el 28 de junio de 2010; organizadas por sindicato y etiqueta.

\begin{tabular}{lccccc}
\hline & $\begin{array}{c}\text { Interacción en- } \\
\text { tre sindicatos }\end{array}$ & $\begin{array}{c}\text { Circulares } \\
\text { relacionadas } \\
\text { con la crisis }\end{array}$ & $\begin{array}{c}\text { Circulares con } \\
\text { tre sindicaton } \\
\text { y relacionadas } \\
\text { con la crisis }\end{array}$ & Sin etiqueta & $\begin{array}{c}\text { Número total } \\
\text { de circulares } \\
\text { por sindicato }\end{array}$ \\
\hline Sindicato de Conductores & 6 & 4 & 0 & 21 & 31 \\
Comisiones Obreras & 3 & 4 & 0 & 48 & 55 \\
Unión General de Trabajadores & 28 & 4 & 8 & 24 & 64 \\
Solidaridad Obrera & 18 & 7 & 8 & 41 & 74 \\
Sindicato Libre & 3 & 2 & 1 & 56 & 62
\end{tabular}

\footnotetext{
No me centro en el transcurso de la huelga total ni en su resultado. Esto permite al lector relacionarse mejor con la sensación de incertidumbre que experimentaron las/os trabajadoras/es y las/os representantes sindicales durante los días, semanas y meses anteriores a la huelga total.
} 


\begin{tabular}{|c|c|c|c|c|c|}
\hline Sindicato de Técnicos & 8 & 0 & 1 & 5 & 14 \\
\hline Sindicato de Estaciones & 2 & 2 & 1 & 18 & 23 \\
\hline Circulares colectivas ${ }^{\text {a }}$ & 4 & N/A & 3 & N/A & 7 \\
\hline Comité de empresa ${ }^{\mathrm{b}}$ & 15 & N/A & 5 & $\mathrm{~N} / \mathrm{A}$ & 20 \\
\hline Total de la columna & 87 & 23 & 27 & 213 & 350 \\
\hline $\begin{array}{l}\text { Las circulares colectivas fu } \\
\text { cato de Conductores. Todas } \\
\text { se aplican. }\end{array}$ & 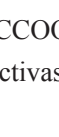 & brera & & $\begin{array}{l}\text { salvo } \\
\text { etique }\end{array}$ & $\begin{array}{l}\text { én por el Sindi- } \\
\text { sin etiqueta" no }\end{array}$ \\
\hline $\begin{array}{l}\text { Las circulares publicadas } p \\
\text { todos los miembros para se }\end{array}$ & ipresa & $\begin{array}{l}\text { obadas } \mathrm{p} \\
\text { culares d }\end{array}$ & $\begin{array}{l}\text { idicat } \\
\text { apresa }\end{array}$ & $\begin{array}{l}\text { itan al m } \\
\text { interacci }\end{array}$ & $\begin{array}{l}\text { yoría simple de } \\
\text { ndicatos, por lo }\end{array}$ \\
\hline
\end{tabular}

Para facilitar el análisis de las circulares seleccionadas, feché, acredité y resumí todas las referencias a otros actores, así como los marcos relacionados con la crisis. Por último, organicé los resúmenes por orden cronológico, para así ubicar las interacciones y los marcos y, por lo tanto, permitir un análisis orientado a los procesos.

El núcleo del análisis se centra en el período entre el anuncio del presidente del gobierno Zapatero (PSOE) de las medidas de austeridad el 12 de mayo y la decisiva asamblea de trabajadoras/es de Metro de Madrid que tuvo lugar el 17 de junio, cuando decidieron convocar una huelga total si se mantenían los recortes salariales. Complemento los datos de esta asamblea de trabajadoras/es, de la que no existen actas, con entrevistas semi-directivas, realizadas durante nueve meses de trabajo de campo con las/os trabajadoras/es de Metro de Madrid, en los años 2016 y 2017. La combinación de circulares y entrevistas permite una reconstrucción precisa de las secuencias de interacción que se produjeron antes de la huelga total.

\section{Cómo se produjo la huelga total}

A principios de 2010, España ya se veía duramente afectada por la crisis económica: el país llevaba seis trimestres consecutivos con un crecimiento negativo del PIB y la tasa de desempleo rozaba el 20\%. Sin embargo, Metro de Madrid parecía una especie de isla afortunada frente a esta situación. Un convenio colectivo firmado en junio de 2009 estipulaba unos incrementos salariales anuales de 750 euros para los años 2009 y 2010. Además, se habían incluido varios complementos salariales en el sueldo básico y se reducía la jornada laboral anual (Metro de Madrid, 2009). Las condiciones de trabajo en Metro de Madrid, en lugar de deteriorarse, en realidad habían mejorado desde el inicio de la crisis. Así es como las/os trabajadoras/es de Metro de Madrid comenzaban el año 2010.

\subsection{El inicio de 2010: una atención desigual a la crisis económica y conflictos habituales entre los sindicatos}

El hecho de que Metro de Madrid no se hubiera visto afectado por la crisis puede explicar por qué, a principios de 2010, la crisis económica era un tema poco tratado entre la mayoría de los sindicatos en Metro de Madrid. Entre enero y mayo de 2018, solo CCOO, Solidaridad Obrera y UGT publicaron circulares sobre la crisis por separado. El Sindicato de Conductores y el Sindicato Libre firmaron una circular conjunta con CCOO y Solidaridad Laboral, pero no realizaron comentarios sobre la crisis económica en ninguna circular aparte. Los dos sindicatos restantes, el Sindicato de Técnicos y el Sindicato de Estaciones, no abordaron este problema en absoluto. Los cuatro sindicatos que no habían publicado una circular por separado sobre la crisis económica (el Sindicato Libre, el Sindicato de Conductores, el Sindicato de Técnicos y el Sindicato de Estaciones) se limitan a la empresa, y los tres últimos a una sola categoría (conductores, técnicos graduados o trabajadoras/es de las estaciones, respectivamente). Además, estos cuatro sindicatos se definen a sí mismos como "políticamente independientes". En cambio, CCOO, UGT y Solidaridad Obrera se consideran a sí mismos como "sindicatos de clase". La manera en la que los sindicatos se representan a sí mismos en términos más o menos políticos parece explicar por qué algunos de ellos abordaron la crisis económica antes de verse directamente afectados, mientras que otros no.

Si bien los tres "sindicatos de clase trabajadora" se pronunciaron sobre la crisis económica, estos diferían de forma considerable en sus conclusiones políticas. Además, se criticaron fuertemente entre sí. Solidaridad Obrera, por ejemplo, consideró a CCOO y UGT como parte integral del problema ya que participaban en las negociaciones de una reforma del mercado laboral que debilitaría los derechos de las/os trabajadoras/es. Solidaridad Obrera se refirió a estos sindicatos como "sindicatos del régimen" (SO 08.02.2010) o "sindicatos del poder" (SO 15.04.2010). Sin embargo, al mismo tiempo Solidaridad Obrera firmó una circular colectiva junto a CCOO, el Sindicato Libre y el Sindicato de Conductores (CCOO s.f. [09. o 10.02.2010]). ${ }^{6}$ En esta carta, los cuatro sindicatos criticaron al gobierno

Pese a estar firmada por cuatro sindicatos, esta y otras circulares colectivas posteriores han sido atribuidas al sindicato que finalmente la publicó. El 
socialdemócrata por querer elevar la edad de jubilación y aplicar recortes en otras prestaciones sociales. El 11 de febrero, UGT respondió afirmando que se negaba a firmar la circular colectiva porque los otros sindicatos habían rechazado sus enmiendas. En esa misma carta, el sindicato criticó a Solidaridad Obrera por su doble rasero, es decir, por etiquetar a UGT y CCOO como ,sindicatos del poder“ y por, poco después, firmar una circular junto a CCOO (UGT 11.02.2010).

El análisis de las circulares muestra que existieron conflictos adicionales entre los sindicatos. Las circulares de principios de 2010 apuntan a disputas abiertas entre UGT y Solidaridad Obrera. En un número del periódico Contramarcha de Solidaridad Obrera, las/os representantes de UGT eran presentadas/os, por lo visto, como borrachas/ os. A raíz de esto UGT solicitó que Solidaridad Obrera "rectifique públicamente (...) las acusaciones e insultos sin base alguna y que se transmiten en su último panfleto CONTRAMARCHA” (UGT 11.02.2010; énfasis del original). En algunas circulares posteriores, las acciones de Solidaridad Obrera fueron descritas como "infantilismos" (UGT 22.02.2010) y “actitudes facistoides" (UGT 01.03.2010). En términos más generales, UGT lamentó la multiplicidad de sindicatos dentro de Metro de Madrid y declaró que solo CCOO y UGT eran capaces de abordar los desafíos sociales actuales (UGT 25.02.2010). Las disputas abiertas entre UGT y Solidaridad Obrera y las críticas de este último a los "sindicatos del régimen" apuntan a una configuración de Metro de Madrid con varios puntos de conflicto entre los sindicatos. Sin embargo, nada indica que pueda tratarse de algo más que riñas habituales entre los muchos sindicatos que compiten entre sí.

\subsection{El anuncio de las medidas de austeridad: incertidumbre entre los sindicatos y un aislamiento cada vez mayor de UGT}

El 12 de mayo, el presidente del gobierno, el socialdemócrata Zapatero, anunció una serie de medidas de austeridad. Según el gobierno estas medidas tenían como objetivo "consolidar" unos presupuestos generales debilitados. Los recortes incluyeron restricciones sobre el derecho a la jubilación parcial, la congelación de la mayoría de las pensiones de jubilación, la cancelación de los subsidios de natalidad y recortes salariales de un promedio del 5\% para las/ os funcionarias/os.

El anuncio de estas medidas de austeridad generó revuelo entre las/os trabajadoras/es y sindicatos de Metro de Madrid. En el sentido estricto de la palabra, las/os trabajadoras/es de Metro de Madrid no son consideradas/os empleadas/os públicas/os debido a que sus condiciones de trabajo se basan en convenios colectivos negociados aparte. Sin embargo, debido a la titularidad pública de la empresa, las/os trabajadoras/es sí suelen estar relacionadas/os con el sector público. Por esta razón, al principio no quedaba claro si las medidas decretadas afectarían o no a Metro de Madrid.

De todos los sindicatos del metro, Solidaridad Obrera fue el primero en pronunciarse al respecto. En una circular publicada el 17 de mayo, denunció “las cobardes medidas del 'ajustazo' del Gobierno" (SO 17.05.2010) y explicó que aún no estaba claro si la reducción salarial afectaría a empresas financiadas con fondos públicos como Metro de Madrid. Si este fuera el caso, afirmaba el sindicato, debían convocarse movilizaciones de manera inmediata. En los días posteriores, CCOO, el Sindicato de Conductores, el Sindicato Libre y Solidaridad Obrera publicaron una circular colectiva alegando que la "agresión sufrida por los empleados públicos es lo suficientemente grave para que todos los Sindicatos y el Comité de Empresa de Metro demos una respuesta unitaria contra las medidas del Gobierno" (CCOO s.f. [muy probablemente 18.05.2010]). El 19 de mayo, UGT emitió una circular en la que afirmaba decir "LA VERDAD SOBRE LAS MEDIDAS" (UGT 19.05.2010, énfasis del original). Sin embargo, en esta carta, el sindicato no hizo referencia a ninguna de las medidas de austeridad. En cambio, culpó a las instituciones financieras y a la derecha de provocar la crisis económica.

El 24 de mayo, las medidas de austeridad fueron publicadas a través de un Real Decreto-ley (RDL 8/2010) en el Boletín Oficial del Estado. Ese mismo día, cuatro sindicatos publicaban por separado circulares al respecto. El Sindicato de Conductores resumió el decreto sin adoptar una postura. Hizo especial hincapié en las disposiciones relativas a las jubilaciones parciales y destacó que estos recortes no afectarían a Metro de Madrid debido al convenio colectivo entonces vigente (SCMM 24.05.2010). CCOO también lanzó un mensaje claro sobre las jubilaciones parciales. Respecto a las demás medidas, el sindicato declaró que se facilitaría más información tan pronto se pudiera evaluar el "grado de afectación en el ámbito de la empresa" (CCOO 24.05.2010). Solidaridad Obrera describió el "ajustazo" adoptado como un "robo" legal "a los bolsillos de los trabajadores", e hizo un llamamiento a responder a las medidas. El sindicato criticó a "los sindicatos del poder" por limitar sus movilizaciones contra este decreto a una huelga de un solo día en el sector público (el 8 de junio) y por seguir considerando la posibilidad de firmar una reforma del mercado laboral, lo que reduciría los costes del despido, aumentaría los contratos de trabajo temporales, fomentaría los sistemas privados de pensiones y elevaría la edad de jubilación (SO 24.05.2010). En la misma carta, el sindicato declaró que la única respuesta posible era la "HUELGA GENERAL hasta echar [para] atrás las medidas del gobierno y del FMI [Fondo Monetario Internacional]" (SO 24.05.2010; énfasis del original). Por su parte, UGT emitió una circular declarando que "tal y como lo esperábamos" las medidas centrales del decreto no afectarían a Metro de Madrid. Además, criticó a CCOO, al Sindicato de Conductores, a Solidaridad Obrera y al Sindicato Libre por "hacer el juego a la derecha" al tergiversar varios aspectos del decreto (UGT 24.05.2010). UGT hizo un llamamiento a "la

hecho de que la circular fuera entregada por CCOO sugiere que este sindicato también fue quien impulsó dicha circular. 
prudencia y la espera" pero advirtió que el sindicato también ejercería presión, llegando a una huelga general si el gobierno imponía de manera unilateral una reforma del mercado laboral. El último sindicato en publicar una circular por separado fue el Sindicato de Estaciones, que declaró que las disposiciones relativas a las jubilaciones parciales no iban a afectar a Metro de Madrid (SEMM 31.05.2010). Se hace visible que CCOO, el Sindicato de Conductores, Solidaridad Obrera y el Sindicato Libre rechazaron las medidas de austeridad de Zapatero. UGT, por su parte, no defendió de manera clara los recortes, pero tampoco los criticó.

En la última semana de mayo, CCOO, el Sindicato Libre y Solidaridad Obrera (esta vez sin el Sindicato de Conductores) publicaron otra circular colectiva titulada "El compromiso político de UGT" (CCOO s.f. [entre el 24.05 y el 01.06.2010]) en el que denunciaban que "la Sección Sindical de UGT en Metro antepone las directrices políticas de su partido a la defensa de los trabajadores" (CCOO s.f. [entre 24.05-01.06.2010]). UGT respondió a esto enseguida. En una carta titulada "Una estrategia política sin seso de CCOO-Metro", el sindicato contraatacaba diciendo:

Cada día que pasa nos sorprenden menos las iniciativas de los máximos responsables de CCOO en Metro. Su intención de dar a entender a la Dirección que son capaces de controlar y dirigir el espectro sindical en nuestra empresa, les lleva, patéticamente, a no escatimar oportunidad alguna, mal entendida, para arrastrar a sindicatos sin sentido sindical como Solidaridad Obrera y el Sindicato Libre en su desvarío. [...]Solidaridad Obrera, su única razón de ser [siendo] las liberaciones sindicales conseguidas, y el Sindicato Libre, [siendo un] sindicato amarillo inventado por un antiguo Jefe de Personal, hoy RR.HH., para debilitar a los sindicatos de clase (UGT 02.06.2010).

UGT declaró además que el gobierno estatal había adoptado muchas políticas de izquierdas y de carácter progresista. Sin embargo, el sindicato insistió en que tomaría medidas, sin descartar una huelga general, si se atacaban las condiciones de trabajo.

Todas estas cartas indican que la preocupación principal de los sindicatos eran las posibles consecuencias que las medidas de austeridad pudieran tener en la empresa. Cuando quedó claro que los recortes no iban a afectar a Metro de Madrid, ninguno de los sindicatos siguió haciendo llamamientos a acciones específicas por parte de las/os trabajadoras/os de la compañía. Los sindicatos también se abstuvieron de unirse a la huelga general del sector público el 8 de junio, convocada por CCOO, UGT y la Central Sindical Independiente y de Funcionarios (CSIF) a nivel estatal. Aun así, la capacidad del gobierno estatal para influir sobre el destino de las/os trabajadoras/es de Metro de Madrid se había puesto de manifiesto. De todos los sindicatos de la empresa, UGT fue el único que continuó defendiendo al gobierno socialdemócrata, lo que fue muy criticado por el resto de los sindicatos. En consecuencia, UGT fue quedándose cada vez más aislada en la configuración sindical de Metro de Madrid.

\subsection{Los recortes llegan a Metro de Madrid: los sindicatos se unen frente al menoscabo de los procedimientos habituales de negociación colectiva}

Tras un turbulento mes de mayo, parecía que las acciones sindicales en Metro de Madrid volvían a la normalidad. Sin embargo, este período de mayor tranquilidad no duró mucho. El 10 de junio, el Consejo de Gobierno de la Comunidad de Madrid, gobernada por el Partido Popular, publicó un proyecto de ley con medidas de aplicación urgente para el Real Decreto-ley 8/2010. Al contrario que el gobierno estatal, que había excluido de manera clara a las empresas públicas de los recortes, el Consejo de Gobierno de la Comunidad de Madrid realizó una propuesta para incluirlas y mencionó de manera específica a Metro de Madrid.

Al día siguiente, tres sindicatos publicaron circulares con llamamientos a la acción. El Sindicato Libre informó de la nueva situación y convocó una asamblea general de trabajadoras/es el 17 de junio. En esta asamblea, las/os trabajadoras/es de Metro de Madrid debían decidir sobre „las medidas de presión que se consideren oportunas“ (SLMS 11.06.2010) para defender el convenio colectivo. En su circular, Solidaridad Obrera afirmó que "[1] os trabajadores de Metro no vamos a permanecer calladitos mientras nos roban el 5\% de nuestro salario" (SO 11.06.2010). Además de una huelga general contra el Real Decreto-ley y la inminente reforma del mercado laboral, el sindicato propuso movilizaciones específicas de Metro de Madrid en defensa del convenio colectivo: "[P]ropondremos a los sindicatos con los que venimos trabajando en unidad [...] (SCMM, CCOO y SLMS) la celebración de una Asamblea General urgente" (SO 11.06.2010). UGT calificó los planes del gobierno regional de "ilegales" porque violaban el derecho constitucional a la negociación colectiva (UGT 11.06.2010). El 14 de junio, el Sindicato de Estaciones también emitió una circular argumentando que los planes de reducción de salarios y la violación del convenio colectivo hacían necesaria una "respuesta contundente" (SEMM 14.06.2010).

Al ampliar los recortes, el gobierno regional pretendía anular las cláusulas del convenio colectivo que se encontraba en vigor en Metro de Madrid, en particular los incrementos salariales estipulados para 2009 y 2010. Esta repentina ampliación de las medidas de austeridad hacia las/os trabajadoras/es de Metro de Madrid resultó inesperada y provocó la indignación de los sindicatos. Al violar el convenio colectivo vigente, el gobierno regional debilitaba las bases de la negociación colectiva. El mensaje no supuso únicamente un "shock moral" (Jasper, 1997), sino que también fue considerado una traición a las normas habituales para la solución de conflictos. De acuerdo a estas normas, un convenio colectivo era vinculante y, en todo caso, cualquier modificación del mismo debería siempre pasar por un proceso de negociación colectiva que incluyera al comité de empresa. Bajo esta perspectiva, la implantación unilateral de un recorte salarial por parte del gobierno regional debilitó la reciprocidad y las garantías de los intercambios rutinarios previos. En palabras de Thompson (1971), el anuncio del gobierno puede considerarse una ruptura de la 
"economía moral" entre las/os trabajadoras/es, los sindicatos, la administración de la empresa y, en última instancia, el gobierno regional.

Apareció en ese momento una oposición común hacia los recortes salariales entre los sindicatos de Metro de Madrid. Sin embargo, esto no fue suficiente para evitar algunas de las antiguas divisiones: en una circular del 14 de junio, $\mathrm{CCOO}$ criticó que "algunos sindicatos" (refiriéndose probablemente a los sindicatos "políticamente independientes") dentro de Metro de Madrid habían pensado que no tenían nada en común con las/os empleadas/ os públicas/os y que "algún sindicato" en particular (refiriéndose claramente a UGT) incluso había justificado los recortes del gobierno estatal (CCOO 14.06.2010). De manera más sutil, UGT condenó a Solidaridad Obrera por su última circular, en la que explicaba que solo existía unidad entre Solidaridad Obrera, CCOO, el Sindicato de Conductores y el Sindicato Libre, dejando de lado a UGT. Al criticar esta afirmación, UGT argumentó que "no hay que tener la más mínima fisura en la unidad sindical“" cuando se trata de responder al ataque del gobierno regional (UGT 14.06.2010).

La ampliación de los recortes salariales llevó a más actores al primer plano de la configuración de Metro de Madrid: las críticas en las circulares ya no apuntaban a un gobierno central distante, sino que se dirigían a un gobierno regional más tangible y a sus organismos dependientes. De hecho, los sindicatos instaron a convocar reuniones con el Consejero Delegado (designado directamente por el presidente de la Comunidad de Madrid) y el Director Gerente (designado por el Consejero Delegado) antes de la asamblea general de trabajadoras/es del 17 de junio.

El 16 de junio, un día antes de la asamblea general de trabajadores, UGT presentó los planes de acción que la comisión permanente del comité de empresa había decidido ese mismo día. Los sindicatos acordaron dos manifestaciones y tres días de huelga. Las manifestaciones debían tener lugar el 24 de junio, cuando se votarían las enmiendas al proyecto de ley en la Asamblea de Madrid, y el 28 de junio, cuando se votaría el proyecto de ley final. Además de las manifestaciones, se propusieron huelgas del 28 al 30 de junio. Según UGT, todos los sindicatos estaban a favor de una huelga de 24 horas el 28 de junio. Al parecer CCOO y el Sindicato Libre querían que las/os trabajadoras/es decidieran sobre el alcance de la huelga para los dos días siguientes (UGT 16.06.2010).

Los llamamientos a la acción sindical pretendían presionar a la administración de la empresa y al gobierno regional. Sin embargo, estas amenazas no dieron los resultados deseados, al menos en un principio. El día antes de la asamblea, y también el mismo día, se produjeron una serie de reuniones entre los sindicatos y la administración de la empresa. Pero estas reuniones no llevaron a "ningún tipo de aclaración" (SLMS 18.06.2010) ya que "ninguno de los representantes de la empresa supieron o quisieron dar explicaciones" (SEMM 17.06.2010). Quedaba claro que las/ os representantes de la decisión del gobierno no estaban dispuestas/os a (o no se les permitía) participar en ningún tipo de diálogo y menos aún alcanzar un acuerdo. Este rechazo total por parte de la empresa impidió que se pudiera resolver el conflicto mediante las negociaciones y contribuyó a intensificar el conflicto.

\section{4. "Y yo más, y yo más": una asamblea de trabajadoras/es con una fuerte competencia entre representantes sindicales}

La oposición de los sindicatos a los recortes resultó tan evidente como la negativa de la administración de la empresa a (re)negociar los recortes. En estas circunstancias, la posibilidad de una huelga se hizo cada vez más probable. No obstante, si bien los sindicatos compartían su oposición a los recortes, no estuvieron de acuerdo en la magnitud de las acciones a tomar. Todo parecía depender de la asamblea de trabajadoras/es del 17 de junio, donde había que decidir sobre las iniciativas que se llevarían a cabo.

Lamentablemente, las circulares solo ofrecen una información parcial sobre cómo transcurrió la asamblea. Por eso he recurrido a las entrevistas realizadas a las/os trabajadoras/es y a las/os representantes sindicales con el fin de comprender qué sucedió.

Óscar ${ }^{7}$, conductor y miembro del Sindicato de Conductores, que tenía 35 años en 2010, describió la asamblea de la mañana ${ }^{8}$ de este modo:

Yo fui porque ya se había oído que iba a ser movidita la asamblea y [cuando llegué] estaba petado. Estaba toda la sala a reventar y, bueno, los sindicatos se empezaron a calentar, yo creo, uno tras otro "y yo más, y yo más". Marcos Pereira se calentó. Pedro Romero también se calentó. En principio el Sindicato de Conductores no iba. [Pausa] Tenían de premisa, por lo que yo tengo entendido, tenían de premisa el no saltarse los mínimos. O sea, iban con eso en la cabeza pero, se fueron calentando según fue la asamblea y, tanto ellos como el resto de sindicatos entraron en el juego.

Esta cita destaca algunos aspectos importantes de la asamblea: (1) El inminente recorte salarial había hecho aflorar algunas emociones no solo entre las/os representantes sindicales sino también entre las/os trabajadoras/es, que

Se ha cambiado los nombres y atributos de las personas para garantizar su anonimato.

8 Debido a que Metro de Madrid funciona con turnos de horarios diferentes, y para permitir la asistencia a las reuniones de las/os trabajadoras/es, las asambleas siempre constan de dos partes: una sesión de mañana (que comienza a las 10:00) y la otra de tarde (que comienza a las 18:00). Suele haber una mayor asistencia a las sesiones de la tarde, dado que este horario coincide menos con las horas de trabajo o de descanso (por ejemplo, después de los turnos de noche). 
esperaban una "asamblea movidita". 9 Para comprender el transcurso de la asamblea, debemos tener en cuenta a las/ os trabajadoras/es (y su enfado) además de la tensa atmósfera que se produjo a raíz de que se reunieran y de que la sala estuviera llena "a reventar". (2) Algunas de las personas que intervinieron parecen haber desempeñado un papel fundamental. El hecho de que, seis años después, Óscar aún señala a ciertos individuos indica que le han dejado una profunda impresión. (3) Parece que la asamblea se caracterizó enseguida por una competencia abrumadora, especialmente entre las/os representantes sindicales, que hizo que las personas que interviniesen se alejaran de sus posiciones iniciales.

En relación al ambiente que había durante la asamblea, Óscar comentó:

Todo el mundo estaba de acuerdo:”¡A quién...?” “¡Uhhh! ¡A Barrabás! ¡A Barrabás! ¡A Barrabás! ${ }^{10}$ Esto fue así. En un momento de calentón. Que sí, que era denigrante que nos quitaran un 5\% y eso nunca había sucedido. Desde luego estábamos calientes y muy indignados, o sea, pero, a lo mejor, si hubiera sido más sosegada la asamblea, a lo mejor no se hubiera conseguido [la huelga total].

María, una trabajadora de estación que tenía 54 años en 2010, describió la asamblea de la tarde de manera similar (aunque más escéptica):

No me gustó el ambiente de la asamblea de la tarde a la que yo fui. No me gustó porque me pareció como muy eufórico. Pero una euforia, no sé, como de hincha de fútbol. En el sentido de que: [tono “eufórico”] “¡Hala! Vamos a echar esto abajo". Como si no hubiera ningún tipo de reflexión.

Al igual que las/os representantes sindicales, las/os trabajadoras/es estaban enfadadas/os. También sentían que el gobierno regional y la administración de la empresa los había traicionado. La reunión de las/os trabajadoras/es pareció aumentar su indignación. Al expresar su ira de manera colectiva, como en un partido de fútbol, las/os trabajadoras/es (incluyendo a quienes no habían hablado en público) participaron de manera activa en la dinámica de la asamblea.

Con esta atmósfera acalorada en mente se puede comprender cómo las/os representantes sindicales se implicaron en una competencia feroz. Eduardo, un trabajador de estación y miembro de Solidaridad Obrera que tenía 42 años en 2010, explica cómo su sindicato se vio arrastrado en esta dinámica:

¿Qué pasó en la asamblea? Pues la Soli [Solidaridad Obrera] no llevaba estos paros. Te va a sorprender, pero la Soli no llevaba paros de este tipo, de no respetar los servicios mínimos. Nos vimos abocados a secundarlos porque el que los propuso fue Marcos Pereira. Salió y dijo que nada, ni mínimos ni nada, que p'alante y se cerraba metro. Entonces Martín (un representante de Solidaridad Obrera) estaba en la mesa y me dijo "pues, a ver, Eduardo ¿qué hacemos, tío? ¿Quién esperaba esto?”. No se había consensuado entre sindicatos que se iba a proponer esto. [...] ¡Fíjate el pastel con el que nos encontramos allí! ¿Un tío que sale a exponer esto? ¿La gente aplaudiendo? [...] Para lo que había en aquel tiempo era una asamblea bien concurrida. Pues, digo a Martín "pues, a ver Martín, ¿qué vamos a hacer? Pues hay que tirar p'alante. Ya veremos. A ver lo que ocurre”. Mira, así es como la Soli se había metido en el pastel este.

Al proponer una huelga total, Marcos Pereira marcó un nuevo rumbo. Como explicó Óscar, la siguiente intervención también apoyó la huelga total. Los fuertes y multitudinarios aplausos hacia estas dos intervenciones de representantes de dos sindicatos distintos indican que las lealtades hacia las propias organizaciones perdían fuerza entre las/ os trabajadoras/es presentes en la asamblea. Esto a su vez incrementó la presión sobre las/os demás representantes sindicales, que no tuvieron más remedio que unirse a la convocatoria. El resultado fue una "alineación colectiva" (Ermakoff, 2008) tras una convocatoria de huelga que iba más allá del alcance de todas las propuestas expresadas hasta entonces por cualquiera de los sindicatos.

Que Marcos Pereira premeditara su discurso o no sigue siendo objeto de especulación, pero está claro que su discurso fue tan solo la primera chispa de un proceso que rápidamente escapó a su control. No podía anticipar con certeza cómo recibirían el mensaje las/os trabajadoras/es ni sabía si las siguientes intervenciones aceptarían la propuesta y la apoyarían. Lo que posteriormente pasaría a ser en una de las acciones de resistencia obrera más debatidas desde el estallido de la Gran Recesión en España, no debería considerarse como el resultado de una decisión estudiada al detalle por parte de un grupo homogéneo (por ejemplo, "las/os trabajadoras/es" o "los sindicatos"); más bien se trató de un "efecto de composición" (Elias, 1984) derivado de las interacciones encadenadas entre múltiples actores interdependientes (representantes sindicales y trabajadoras/es por igual).

Considerar la alineación colectiva como un efecto de composición no significa afirmar que los actores actuaran de forma irracional. Las palabras de Eduardo muestran que las/os representantes sindicales entendieron muy bien que se

\footnotetext{
9 Debido a la falta de datos, no me es posible reconstruir las interacciones entre las/os trabajadoras/es de base y sus representantes sindicales antes de la asamblea. Por eso no está claro si (y en qué medida) las iniciativas desde las bases y el aumento de dichas iniciativas antes de la asamblea tuvieron algún efecto sobre el desarrollo de la asamblea.

10 Refiriéndose a un episodio de los evangelios, donde la multitud grita a favor de conmutar la sentencia de muerte de Barrabás en lugar de la de Jesús.
} 
enfrentaban a una "decisión crítica" (Ermakoff, 2008; 2017). Eduardo y su compañero se encontraron visiblemente sorprendidos por la dinámica de la asamblea y su sorpresa se debía precisamente a que entendían que la decisión de convocar una huelga total supondría grandes consecuencias, implicaría una serie de riesgos a título individual y "alteraría de manera considerable la estructura de los costes de otras opciones posteriores" (Ermakoff, 2017: 131). Sin embargo, sus palabras también señalan que hubo representantes sindicales a quienes esto tomó por sorpresa y que no vieron ninguna alternativa viable a la de unirse a la convocatoria de una huelga total. Del lado de las/os trabajadoras/ es, la asistencia multitudinaria indica que muchas/os estaban decididos a ejercer su poder de decisión, lo que finalmente hicieron al unir a los sindicatos y votar a favor de la huelga total.

\subsection{Sin dar marcha atrás, sin reconciliación: punto muerto tras la asamblea de trabajadoras/es}

La asamblea de trabajadoras/es el 17 de junio fue la secuencia decisiva en la génesis de la huelga total. El día después de la asamblea, todas las secciones sindicales, a excepción del Sindicato de Técnicos, publicaron una circular sobre la asamblea. Todas destacaban la unidad que se había alcanzado entre las/os trabajadoras/es y los sindicatos. Esto indica un endurecimiento de la polarizada configuración en el Metro de Madrid: por un lado, el gobierno regional y los organismos dependientes que eran reacios a negociar y más aún a dar marcha atrás en los recortes salariales. Las/os trabajadoras/es y los sindicatos, por otro lado, que habían cerrado filas en su lucha contra las medidas de austeridad.

Todas las circulares destacaban que ambas manifestaciones (el 24 y 28 de junio) estaban confirmadas y que se habían autorizado tres huelgas de una duración de 24 horas del 28 al 30 de junio. En su circular, Solidaridad Obrera comentaba esta decisión (SO 17.06.2010):

La Asamblea ha decidido realizar la huelga del día 28 legalmente, cumpliendo los servicios mínimos; pero si ese día en la Asamblea de Madrid aprueban el Decreto que rompe nuestro convenio, firmado hace exactamente un año, nosotros también rompemos la baraja y la huelga será total, encerrándonos en nuestro local de Plaza de Castilla (donde se celebran las asambleas generales) desde esa misma noche.

Se hace evidente que la ruptura en la economía moral cambió las reglas del juego. Debido a que la empresa y el gobierno regional no respetaron su parte del acuerdo (es decir, el convenio colectivo), las/os trabajadoras/es y los sindicatos consideraron que también ellas/os estaban legitimadas/os a hacer caso omiso de sus obligaciones (es decir, cumplir con los servicios mínimos). Al igual que en los motines del pan en los siglos XVII y XVIII, que tenían como objetivo restaurar las normas para la fijación tradicional de los precios del pan (Thompson, 1971), las/os trabajadoras/ es y los representantes sindicales de Metro de Madrid tenían como objetivo restablecer la negociación colectiva como el proceso autorizado para la resolución de conflictos.

Si bien las circulares de los otros sindicatos incluían argumentos similares, no eran tan explícitas con respecto a la naturaleza de las huelgas adoptadas. CCOO aludió a la huelga total al mencionar que no consideraba a Metro de Madrid como un servicio esencial ${ }^{11}$ (CCOO 18.06.2010). El Sindicato de Estaciones se refirió a la decisión de una manera aún más sutil al hablar de "paro" para el paro laboral del 28 de junio y de "huelga" para los paros laborales del 29 y 30 de junio, lo que da a entender la distinción que se hace habitualmente entre un paro laboral limitado ("paro") y una "huelga" más firme (SEMM 17.06.2010). El Sindicato de Conductores no se refirió a los servicios mínimos, pero declaró que con motivo de la próxima asamblea de afiliadas/os, propondría "mantener o aumentar las movilizaciones" decididas por la asamblea general de trabajadoras/es. Tanto UGT como el Sindicato Libre no hicieron ninguna alusión directa o indirecta a una posible huelga total. Solidaridad Obrera fue, por lo tanto, el único sindicato que habló abiertamente en una circular sobre la decisión tomada por la asamblea de trabajadoras/es. Las prudentes comunicaciones del resto de los sindicatos sugieren que o bien temían la posibilidad de que se produjeran represalias (por ejemplo, demandas judiciales) al convocar una acción potencialmente ilegal o que la decisión los había tomado por sorpresa y que no se encontraban del todo cómodos con el resultado de la asamblea.

Independientemente de si los sindicatos estaban a gusto con la decisión o no, la posibilidad de dar marcha atrás resultó cada vez más difícil. A partir del 18 de julio, los principales periódicos españoles dieron una amplia cobertura a la inminente huelga total. Se pidió constantemente a las/os representantes sindicales (principalmente del Sindicato de Conductores, CCOO y UGT) que justificaran la decisión de la asamblea. En repetidas ocasiones declararon que la huelga total solo se revocaría si se retiraban los recortes que afectaban a Metro de Madrid. En estas circunstancias, dar marcha atrás por parte de los sindicatos habría implicado una considerable pérdida de credibilidad: la asistencia a la asamblea había sido demasiado multitudinaria, ${ }^{12}$ su decisión demasiado unánime, ${ }^{13}$ y los sindicatos (especialmente los principales) tuvieron que defender y reforzar públicamente, y con demasiada frecuencia, la decisión de la asamblea. Ninguno de los principales sindicatos asumió este riesgo. Únicamente los dos sindicatos menores, el Sindicato

11 A los que se les aplican servicios mínimos, véase la Nota 1.

12 Las cifras de asistencia variaban entre "más de 1.000" (SO 17.06.2010), 1.050 (CCOO 18.06.2010) y "más de 1.200" (UGT 18.06.2010). La cifra más exacta la ofreció Solidaridad Obrera, que precisó que habían asistido a la asamblea 328 trabajadoras/es por la mañana y 694 por la tarde (SO 17.06.2010). Esto corresponde a un total de 1.022 trabajadoras/es de 7.624 empleadas/os en total (Metro de Madrid, 2010).

13 Es decir, "por prácticamente unanimidad" (UGT 18.06.2010) o con solo dos votos en contra y una abstención (CCOO 18.06.2010). 
de Técnicos y el Sindicato de Estaciones, declararon unos días después que no formaban parte del comité de huelga (Sindicato de Técnicos) o que se habían retirado de dicho comité (Sindicato de Estaciones). Sin embargo, en ambos casos, el argumento que esgrimieron no era un desacuerdo con la decisión de la asamblea sino una aparente falta de consideración por parte de los demás sindicatos (SEMM 21.06.2018; STMM 22.06.2018).

La única opción que quedaba para suspender la huelga era realizar enmiendas al proyecto de ley, lo que habría conducido a excluir a Metro de Madrid de los recortes. Sin embargo, a diferencia del campesinado de los siglos XVII y XVIII, que podía contar con el apoyo de la "tradición paternalista de las autoridades" (Thompson, 1971: 79) para así deshacer el aumento ilegítimo del precio del pan o de la harina, las/os trabajadoras/es de Metro de Madrid no podían esperar apoyo alguno por parte del gobierno regional conservador. Es más, la autoridad aquí constituía precisamente la parte agresora (y se encontraba además demasiado dispuesta a introducir las medidas de austeridad en el sector público). En esos momentos, la configuración de Metro de Madrid se caracterizaba por una situación de estancamiento con unas posiciones cada vez más rígidas y antagónicas.

El 24 de junio tuvo lugar una primera manifestación de gran afluencia frente a la Asamblea de Madrid, pero la enmienda para exceptuar las empresas públicas de los recortes no logró los votos suficientes. El 28 de junio fue el primer día de huelga que respetaba los servicios mínimos. Al final de la tarde de ese mismo día, las/os trabajadoras/ es de Metro de Madrid se manifestaron nuevamente frente a la Asamblea de Madrid, donde se iba a votar la versión definitiva del proyecto de ley. Dicho proyecto de ley fue aprobado con el apoyo del Partido Popular, la abstención del PSOE y el rechazo de Izquierda Unida. Justo después de la votación final del parlamento autonómico, las/os trabajadoras/es de Metro de Madrid se reunieron en otra asamblea de trabajadoras/es. Ninguna intervención cuestionó (o se atrevió a cuestionar) la decisión tomada en la asamblea anterior. Sin más votaciones formales, las/os trabajadoras/es y representantes sindicales se dividieron en grupos más pequeños y comenzaron a organizar los piquetes para garantizar la huelga total de los siguientes días. ${ }^{14}$

\section{Algunas conclusiones}

En este artículo, mi objetivo era identificar e interpretar las secuencias de interacción previas a uno de los principales conflictos laborales en la historia reciente de España: la huelga total de 48 horas en el Metro de Madrid en junio de 2010. Con este fin, adopté una perspectiva interaccionista (Biggs, 2002; Fillieule y Broqua, 2020; Jasper y Duyvendak, 2015) y examiné las circulares sindicales redactadas durante el transcurso de los eventos, así como las entrevistas semi-directivas realizadas posteriormente con representantes sindicales y trabajadoras/es.

El análisis ha permitido distinguir cinco grandes secuencias de interacción. La primera secuencia comienza a principios de 2010 y dura hasta principios de mayo. Durante esta secuencia, pocos sindicatos de la empresa hablaron de la crisis económica en sus circulares. Estas circulares muestran algunas tensiones entre los sindicatos, pero nada indica que fueran más allá de disputas habituales entre sindicatos. La segunda secuencia comienza el 12 de mayo. Ese día, el gobierno central socialdemócrata anunció medidas de austeridad para el sector público. Este anuncio generó incertidumbre entre los sindicatos de Metro de Madrid ya que al principio no quedaba claro hasta qué punto las medidas se aplicarían a empresas públicas como Metro de Madrid. Esta incertidumbre vino acompañada del aislamiento cada vez mayor de UGT que, como único gran sindicato, no se distanció del gobierno central. La tercera secuencia comienza el 10 de junio. Este fue el día en que el gobierno regional de Madrid anunció un proyecto de ley para extender los recortes a las empresas públicas, mencionando de manera explícita a Metro de Madrid. Con este anuncio, el gobierno regional debilitó los fundamentos de la negociación colectiva dentro de la empresa y unió a los sindicatos en una resistencia compartida contra los recortes. Sin embargo, mientras se movían juntos, los sindicatos no llegaron a una postura común con respecto al alcance de las acciones necesarias para evitar los recortes salariales. La cuarta secuencia se limita a la asamblea de trabajadoras/es el 17 de junio. Durante esta asamblea, las/os trabajadoras/es y las/os representantes sindicales convergieron en un llamamiento a una huelga total, superando todas las reivindicaciones expresadas anteriormente por cualquier sindicato. El análisis de la asamblea muestra que la "alineación colectiva" (Ermakoff, 2008) no fue un acto colectivo premeditado sino el resultado de un "efecto de composición" (Elias, 1984): una fuerte competencia entre las/os representantes sindicales que se vio intensificada por los multitudinarios aplausos de las/os trabajadoras/es. El resultado fue una secuencia final que duró del 18 al 28 de junio y que estuvo marcada por alcanzar un punto muerto, además de por una serie de posiciones cada vez más polarizadas y ancladas en la configuración de Metro de Madrid: por un lado, el gobierno regional, y sus organismos dependientes, que no estaba dispuesto a negociar, y mucho menos a dar marcha atrás en los recortes salariales. Por otro lado, los principales sindicatos, que se vieron obligados a defender (y reforzar) públicamente la decisión tomada por las/os trabajado-

\footnotetext{
Considerar la huelga total como un éxito o no depende de la interpretación que se haga. Durante la huelga, la dirección de la empresa se negó a negociar. Tras 48 horas de inactividad total, las/os trabajadoras/es, muchos de las/os cuales temían duras represalias, incluidos despidos, cedieron y reanudaron los servicios mínimos para permitir el comienzo de las negociaciones. A continuación, siguieron cuatro días más de huelga y numerosas reuniones entre el comité de huelga y la administración de la empresa. En una asamblea general de trabajadoras/es el 17 de julio, la mayoría de las personas asistentes finalmente aceptaron un acuerdo preliminar que contaba con el apoyo de la mayor parte del comité de huelga (Sindicato de Conductores, CCOO, UGT y Sindicato Libre), pero con la oposición de Solidaridad Obrera. El acuerdo mantenía el recorte de un $5 \%$ en gastos de personal. Sin embargo, al reducir los gastos de personal y no los salarios (por ejemplo, los gastos relacionados con la formación profesional o sin cubrir las plazas vacantes), el recorte en los salarios reales se redujo primero a $1 \%$ y en última instancia (a través de un ajuste de la cuota obrera) a $0,84 \%$.
} 
ras/es, haciendo prácticamente imposible cualquier tipo de retracción. La intensificación del conflicto también se refleja en la evolución de las circulares que hacen referencia a la crisis económica (véase Figura 1).

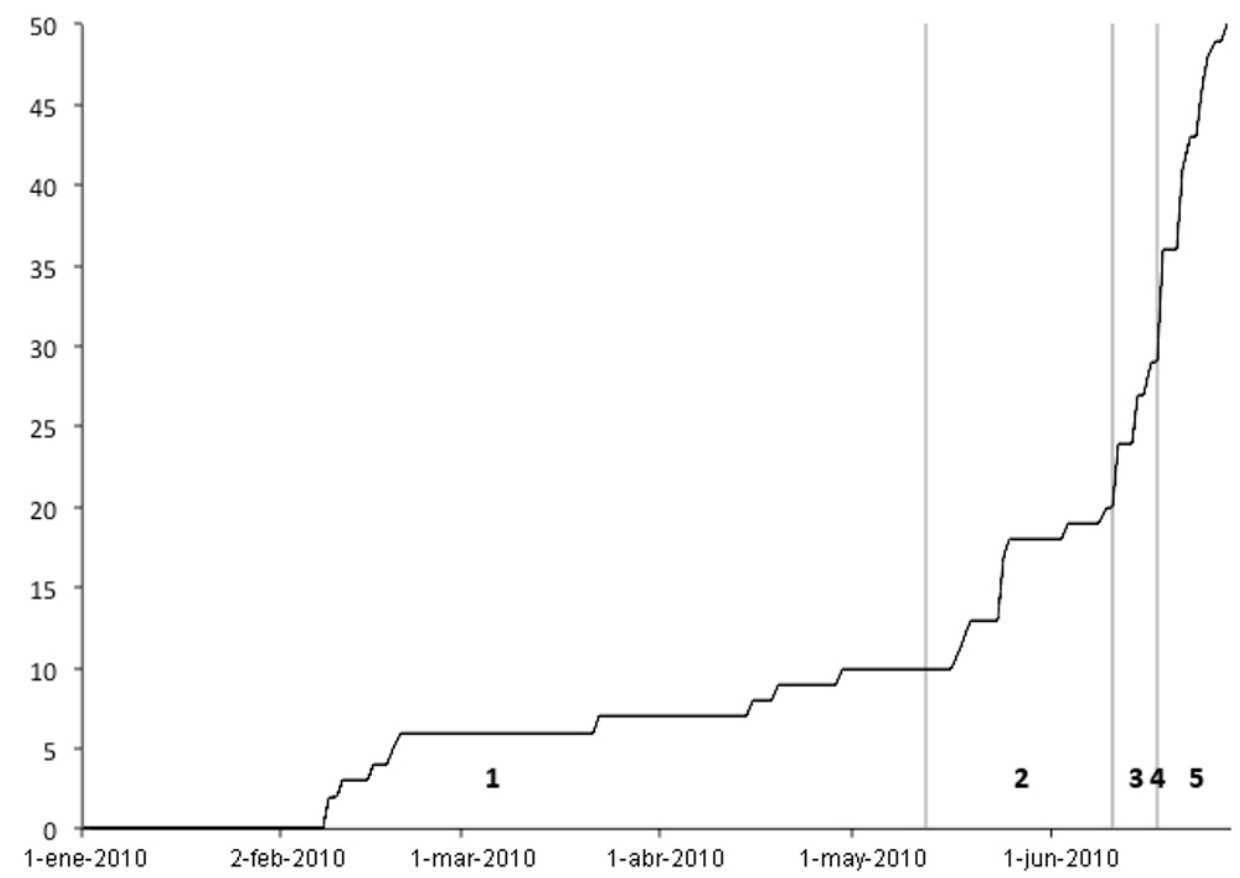

Figura 1. Número total de circulares relacionadas con la crisis y publicadas entre el 1 de enero de 2010 y el 28 de junio de 2010. Las cinco secuencias están separadas por líneas grises y la secuencia 4 es tan solo una línea gris. Fuente: elaboración propia.

En términos metodológicos, esta investigación destaca por su análisis sistemático de los materiales que se crearon durante el transcurso de los eventos. Al sacar a la luz las configuraciones cambiantes de los actores implicados, así como los momentos de fricción e incertidumbre, estos materiales han contribuido a evitar una reconstrucción excesivamente lineal a posteriori (Dobry, 2009). Además, las circulares permitieron incluir no solo las interacciones verticales (por ejemplo, entre los sindicatos y la dirección de la empresa) sino también los intercambios producidos de manera horizontal (en particular entre los diferentes sindicatos), que han demostrado ser esenciales para dar lugar a una huelga total.

El análisis de las interacciones horizontales apunta a una cuestión que merece una consideración adicional: la ambigua relación entre la competencia que existe entre los sindicatos y el recrudecimiento de los conflictos laborales. De hecho, la competencia entre los sindicatos parece haber contribuido tanto a la contención inicial como al incremento posterior del conflicto laboral. Durante las secuencias iniciales, algunos sindicatos expresaron la necesidad de llevar a cabo acciones reivindicativas. Sin embargo, ninguno de estos sindicatos se arriesgó a traducir dichos llamamientos en acciones concretas. Al parecer, los sindicatos temían que, de no obtener un apoyo suficiente por parte de las/os trabajadoras/es, los sindicatos más reacios se verían reforzados. Por otro lado, la competencia entre los diferentes sindicatos también resultó clave para la dinámica de la decisiva asamblea de trabajadoras/es, donde las/os representantes sindicales no tuvieron más remedio que unirse a la convocatoria de una huelga total. También durante el punto muerto posterior, la competencia entre los sindicatos impidió que estos (al menos los más grandes) dieran marcha atrás. En estas sucesiones en aumento, abandonar la convocatoria se habría identificado con un acto de cobardía y el resto de los sindicatos habría sacado provecho del sindicato que "cedía". Se necesita profundizar más en la investigación para entender mejor cómo contribuye la competencia entre sindicatos a la contención de conflictos laborales, y cuándo y cómo pasa a agudizarlos.

Si bien logré reconstruir las interacciones entre los sindicatos, la restricción de datos limitó la posibilidad de incluir las interacciones horizontales producidas en distintos niveles. Una investigación futura podría llenar este vacío al examinar el modo en el que las relaciones de competencia en el seno de los demás grupos de actores (trabajadoras/ es, administraciones de empresas o gobiernos) pueden contribuir tanto a la contención como al aumento de los conflictos laborales.

La perspectiva interaccionista adoptada en este artículo ha permitido comprender las dinámicas procesuales e identificar las secuencias fundamentales que dieron lugar a la huelga total. Esta perspectiva también podría constituir una contribución importante para los estudios recientes que examinan las "coyunturas críticas"15 desde la perspec-

15 Las “coyunturas críticas" se definen aquí como períodos de “crisis o tensión que las políticas e instituciones existentes no son capaces de resolver" (Roberts, 2015, p. 65). 
tiva de los movimientos sociales (Della Porta, 2018). La inclusión de secuencias de interacción que preceden a los eventos de protesta podría resultar útil para refutar aún más la "inevitabilidad" (Dunning, 2017), o su contraparte, la "espontaneidad" (Flesher Fominaya, 2014), a menudo atribuida a los eventos de protesta masiva que desencadenan coyunturas críticas.

Centrarse en las interacciones también contribuye a una mejor comprensión de las contrapartidas de las protestas multitudinarias: los períodos (muchas veces largos) de relativa quiescencia. La génesis de la huelga total aquí estudiada muestra las grandes dificultades que atravesaron los sindicatos para romper con las normas y convenciones que suelen orientar sus interacciones con la administración de la empresa en tiempos normales. De este modo, la perspectiva interaccionista permite comprender la quiescencia y el conflicto laboral de forma relacional, es decir, como dos caras de una misma moneda.

\section{Bibliografía}

Biggs, M. (2002). "Strikes as Sequences of Interaction: The American Strike Wave of 1886“, Social Science History, 26(3), 583-617.

Della Porta, D. (2018)."Protests as Critical Junctures: Some Reflections Towards a Momentous Approach to Social Movements“, Social Movement Studies. DOI: 10.1080/14742837.2018.1555458

Dobry, M. (2009). Sociologie des crises politiques. Les Presses de Sciences Po, Paris.

Dunning, T. (2017). "Contingency and determinism in research on critical junctures", Qualitative \& Multi-Method Research, 15(1), 41-47.

Duyvendak, J. W. y Fillieule, O. (2015). "Patterned Fluidity: An Interactionist Perspective as a Tool for Exploring Contentious Politics“, en Jasper, J. M. y Duyvendak J. W. (coord.), Players and Arenas: The Interactive Dynamics of Protest, Amsterdam University Press, Amsterdam, 134-149.

Elias, N. (1984). What Is Sociology?, Columbia University Press, New York.

Ermakoff, I. (2008). Ruling Oneself Out: A Theory of Collective Abdications, Duke University Press, Durham.

Ermakoff, I. (2017). "Shadow Plays: Theory’s Perennial Challenges“, Sociological Theory, 35(2), 128-137.

Fillieule, O., y Broqua, C. (2020). "Sexual and Reproductive Rights Movements and Counter Movements from an Interactionist Perspective“, Social Movement Studies, 19(1), 1-20. DOI: 10.1080/14742837.2019.1709434

Flesher Fominaya, C. (2015). "Debunking Spontaneity: Spain's 15-M/Indignados as Autonomous Movement", Social Movement Studies, 14(2), 142-163. DOI: 10.1080/14742837.2014.945075

Franzosi, R. (1995). The Puzzle of Strikes: Class and State Strategies in Postwar Italy, Cambridge University Press, Cambridge. Goudsblom, J. (1977). Sociology in the Balance, Blackwell, Oxford.

Jabola-Carolus, I., Elliott-Negri, L., Jasper, J. M., Mahlbacher, J., Weisskircher, M. y Zhelnina, A. (2018). "Strategic Interaction Sequences: The Institutionalization of Participatory Budgeting in New York City“, Social Movement Studies. DOI: 10.1080/14742837.2018.1505488

Jasper, J. M. (1997). The Art of Moral Protest: Culture, Biography, and Creativity in Social Movements, University of Chicago Press, Chicago.

Jasper, J. M. (2015). "Introduction: Playing the Game“, en Jasper, J. M. y Duyvendak J. W. (coord.), Players and Arenas: The Interactive Dynamics of Protest, Amsterdam University Press, Amsterdam, 9-32.

Jasper, J. M., y Duyvendak, J. W. (coord.). (2015). Players and Arenas: The Interactive Dynamics of Protest, Amsterdam University Press, Amsterdam.

Mayring, P. (2014). Qualitative Content Analysis: Theoretical Foundation, Basic Procedures and Software Solution, Beltz, Klagenfurt.

Metro de Madrid. (2009). Convenio Colectivo 2009-2012, Metro de Madrid, Madrid.

Metro de Madrid. (2010). Informe Anual 2010, Metro de Madrid, Madrid.

Pohl, N. (2016). "Quand les hiérarchies reviennent par la fenêtre... La démocratie au sein d'un syndicat anarcho-syndicaliste“, IEPHI Working Paper Series, 65, UNIL, Lausanne.

Pohl, N. (2019). "How Strikes Can Arise: Sequences of Interaction in the Genesis of a Total Strike in Madrid Underground“, Social Movement Studies, DOI: 10.1080/14742837.2019.1708310

Roberts, K. (2015). Changing Course in Latin America: Party Systems in the Neoliberal Era, Cambridge University Press, Cambridge.

Snow, D. A. y Benford, R. D. (1988). “Ideology, Frame Resonance, and Participant Mobilization“, International Social Movement Research, 1(1), 197-217.

Snow, D. A., Rochford, E. B., Worden, S. K. y Benford, R. D. (1986). "Frame Alignment Processes, Micromobilization, and Movement Participation“, American Sociological Review, 51, 464-481.

Tackett, T. (1996). Becoming a Revolutionary: The Deputies of the French National Assembly and the Emergence of a Revolutionary Culture (1789-1790), Princeton University Press, Princeton.

Thompson, E. P. (1971). "The Moral Economy of the English Crowd in the Eighteenth Century", Past \& Present, 50, 76-136.

Vivero Serrano, J. B. (2002). La huelga en los servicios esenciales, Lex Nova, Valladolid. 
Winston, C. M. (1982). "The Proletarian Carlist Road to Fascism: Sindicalismo Libre“, Journal of Contemporary History, 17(4), $557-585$. 